\title{
Is the Level of Noise in a School Environment be Harmful to the Hearing of Teachers?
}

\author{
Gabriela Guenther Ribeiro Novanta1® Sergio Luiz Garavelli²® ${ }^{2}$ Andre Luiz Lopes Sampaio ${ }^{3}$
}

1 Department of Speech Language Pathology and Audiology, Centro Universitário Planalto do Distrito Federal (UNIPLAN), Braślia, DF, Brazil

2 Division of Engineering, Centro Universitário de Brasília (UNICEUB), Brasília, DF, Brazil

${ }^{3}$ Laboratory of Otorhinolaringology Research, Universidade de Brasília, Brasília, DF, Brazil

Int Arch Otorhinolaryngol 2020;24(4):e503-e507.

\begin{abstract}
Address for correspondence Gabriela Guenther Ribeiro Novanta, Master, Departamento de Fonoaudiologia, Centro Universitário Planalto do Distrito Federal, Avenida Pau Brasil Lote 2, Brasília, DF, 71916-500, Brazil (e-mail: ribeiro.novanta@gmail.com).
\end{abstract}

\begin{abstract}
Introduction The excessive noise observed in the school environment can cause damages or losses to the learning process as well as risks to the health of teachers and students, such as physical, mental and social impairments, including, among them, hearing loss.

Objective To assess otoacoustic emissions in teachers and determine whether classroom noise reduces distortion-product otoacoustic emissions (DPOAEs) amplitude and signal-to-noise ratio (SNR).

Method Sixty-seven teachers were evaluated using otoacoustic emissions testing in two situations: after hearing rest and after the working day.

Results Signal amplitude $(p=0.044[2 \mathrm{kHz}] ; p=0.01[4 \mathrm{kHz}])$ and SNR for frequencies of $2 \mathrm{kHz}(p=0.008)$ and $4 \mathrm{kHz}(p=0.001)$ decreased significantly between time points.

Keywords

- noise

- faculty

- otoacoustic emissions

- spontaneous Mean classroom noise was associated with the magnitude of the difference in signal amplitude at $2 \mathrm{kHz}(p=0.017)$ and $4 \mathrm{kHz}(p=0.015)$, and SNR at $4 \mathrm{kHz}(p=0.023)$.

Conclusions There was a decrease in the amplitude and in the SNR after exposure to the noise in the classroom environment. The high levels of sound pressure that teachers are exposed to on a daily basis can cause a temporary change in the outer hair cells of the Corti organ, and these changes may become permanent over time.
\end{abstract}

\section{Introduction}

The excessive noise present in schools has been a complaint frequently reported by teachers in Brazil. The classroom, which is often built with inappropriate acoustic requirements or low noise isolation, suffers from both external and internal sources of noise. ${ }^{1-3}$

Factors such as background noise levels, the difference between speech signal and noise, and reverberation time directly influence communication inside the classroom. ${ }^{3,4}$ The American National Standards Institute (ANSI) ${ }^{5}$ recommends that noise in an unoccupied classroom should not

received

April 4, 2019

accepted

December 21, 2019
DOI https://doi.org/

10.1055/s-0040-1702969. ISSN $1809-9777$. exceed $35 \mathrm{~dB}(\mathrm{~A})$, and the difference between the voice of the teacher and the background noise should be more than $15 \mathrm{~dB}$ to the children's ears. Although the Brazilian Association of Technical Norms (ABNT) has established that noise inside the classroom should not exceed $50 \mathrm{~dB}(\mathrm{~A}){ }^{6}$ several studies conducted in Brazil ${ }^{3,4,7,8}$ have reported intensities close to or higher than $60 \mathrm{~dB}(\mathrm{~A})$. Excessive noise can disturb people at work, rest, and sleep, impair hearing, and other physical effects can include muscle tension and increased blood pressure (hypertension). ${ }^{8-12}$ With respect to teachers, the main complaints are related to fatigue, stress, headaches, and anxiety. ${ }^{1,2,8,13}$
Copyright (๔) 2020 by Thieme Revinter Publicações Ltda, Rio de Janeiro, Brazil
License terms

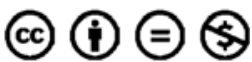


Intense noise exposure may generate temporary or permanent hearing disorders. Temporary threshold shift occurs when the ear reduces auditory sensitivity for a short period of time but is able to recover fully upon cessation of exposure. $^{12}$ The presence of these temporary changes may indicate a susceptibility to permanent hearing loss. ${ }^{12,14,15}$ When a permanent and gradual hearing reduction occurs due to exposure to high levels of sound pressure, the result is noiseinduced hearing loss (NIHL).

Several studies have used distortion-product otoacoustic emissions (DPOAEs) as a means of assessing the functionality of outer hair cells in workers exposed to noise, as this test permits the identification of the beginning of cochlear injury, even before any change can be perceived via audiometry $9,16,17$. The advantage of using DPOAEs refers to the sensitivity in the early identification of changes caused by noise, due to their good record at the frequency of $4 \mathrm{KHz}$, frequency affected by NIHL. ${ }^{17}$ Therefore, DPOAEs can improve the efficacy of hearing preservation programs by providing more direct and reliable measurement of early changes and damage to the inner ear. ${ }^{17,18}$

Within this context, our objective was to assess DPOAEs in a group of teachers in the Federal District of Brazil to determine whether noise in the classroom would reduce the amplitude and signal-to-noise ratio (SNR) of DPOAEs.

\section{Methods}

This was a cross-sectional study involving primary school teachers from four schools that belong to the public school system of Samambaia in the administrative region of the Federal District. The schools were chosen at random by regional education coordinators at sites without marked exposure to sources of external noise, such as construction work, traffic, or industries.

All teachers from the selected schools were invited to participate in the study. Due to the refusal of some professionals, the selected sample consisted of those who agreed to participate in the study. Sixty-seven out of 110 invited teachers were included in this study by self-agreement and fulfillment of the eligibility criteria. The exclusion criteria were the presence of earwax, use of a hearing aid, exposure to occupational noise outside the classroom, inflammatory and infectious diseases of the middle or external ear, and use of common ototoxic drugs (aminoglycoside antibiotics, salicylates, quinine, antineoplastic agents and loop diuretics). No participants were excluded.

\section{Procedure}

The study was conducted in two stages: before the beginning of classroom work (with a hearing rest) and at the end of classes (after the working day). All teachers evaluated had signed a contract to work 40 hours per week, with classroom exposure time corresponding to one shift ( 5 hours of exposure).

The ear canal was initially inspected to determine the presence of ear wax, secretions, and perforation of the tympanic membrane. Teachers were then placed inside a Prostec portable sound proof booth for the examination of DPOAEs. The right ear of each individual was the first to be tested in all cases, followed by the left ear. The DPOAEs equipment used in the present study, Ero-Scan (MAICO Diagnostics, Eden Prairie, MN, USA), automatically monitored noise levels, the linearity of the stimulus during the test, and the appropriate position of the probe. Subsequent to completion of the test, the teachers went to their classrooms and, at the end of the working period, they returned for the second DPOAEs recording. These procedures were followed by teachers working both morning and afternoon shifts. Teachers from the afternoon shift were asked to maintain hearing rest during the morning period.

The following parameters were used for DPOAEs recording, two simultaneous pure tones with different frequencies were used at intensities of P1 (65 dB SPL) and P2 ( $55 \mathrm{~dB}$ SPL), at frequencies of 2, 4, 6 and $8 \mathrm{kHz}$.

For the DPOAEs test, we considered results with amplitudes of -5 decibel sound pressure level (dB SPL) or higher and an SNR of $6 \mathrm{~dB}$ SPL or higher at all four frequencies tested $(2,4,6$, and $8 \mathrm{kHz})$ to have passed. An individual analysis was also performed for each frequency, using amplitude and SNR.

During the classes, measurements were performed inside the classroom to determine teachers' noise exposure levels, assessed that day, using a calibrated $0 \mathrm{~dB}$ SIP95 Sound Level Logging Meter (ACOEM Group, Limonest, France). The instrument was placed parallel to the teacher at a height of $1 \mathrm{~m}$ from the floor and a distance of $1 \mathrm{~m}$.

The SPL was measured in $\mathrm{dB}(\mathrm{A})$ at an equivalent energy level (Leq), which represents average sound energy for a given time. The choice of $\mathrm{dB}(\mathrm{A})$ measurement (A-weighting) was made due to the possibility of measuring SPLs at different frequencies in a manner comparable to the organ of human hearing. ${ }^{19}$ Besides mean acoustic energy, minimum and maximum noise levels were recorded. Our experiment was designed to maintain the routines and behavior of teachers and students in the classroom. For each evaluation, three measurements of 10 minutes in duration were performed in the classroom at intervals of at least 1 hour. In total, 201 recordings were made during the classroom activities with the students in the room.

\section{Instruments and Statistical Analysis}

The SPSS software version 21.0 (IBM Corp., Armonk, NY, USA) was used for data analysis and determination of correlations. Data collected were submitted to descriptive analysis using means and standard deviations. Normality and homogeneity tests were performed to determine the analysis methods.

The differences between the groups were investigated using $t$-tests. An analysis of variance (ANOVA) was used to determine differences between presence of DPOAEs and age and teaching experience. A chi-square test was used to examine the relationships between the presence of DPOAEs and gender.

A paired $t$-test was used to compare the values obtained at the two moments of assessment (via DPOAEs). The Pearson correlation coefficients were used to determine associations between noise level and the differences between DPOAEs range and amplitude and SNR ratio. The level of statistical significance was set at $p<0.05$. 
The study was approved by the Research Ethics Committee of the Faculty of Health Sciences, Universidade de Brasília (Protocol No. 476.166).

\section{Results}

The study included 67 teachers aged between 21 and 54 years (mean 37.1 years; standard deviation $[S D]=8.4$ ), of whom 61 (91\%) were female and 6 (9\%) were male. The duration of their teaching experience ranged from 1 to 27 years (mean 10.7 years $S D=6.8$ ). Comparisons between the 4 schools did not reveal significant differences in teachers' age or duration of teaching experience (paired t-test, $p>0.1$ for all). In addition, no significant differences in DPOAEs were observed between the right and left ears or according to gender (paired $t$-tests, $p>0.1$ for all). Therefore, the data for the teachers of the 4 schools were pooled to total 134 ears.

The mean $( \pm S D)$ noise level during the classroom activities with the students in the room was $76.9 \pm 5.4 \mathrm{~dB}(\mathrm{~A})$, with a range of $59.1 \pm 4.3$ to $90 \pm 7.1 \mathrm{~dB}(\mathrm{~A})$; however, maximum recordings were as high as $128 \mathrm{~dB}(\mathrm{~A})$.

The DPOAEs were classified as FAIL, UNILATERAL PASS, or BILATERAL PASS. A total of $20.9 \%(n=14)$ of the subjects had DPOAEs present at all frequencies in only one ear (UNILATERAL PASS), and $16.4 \%(n=11)$ had DPOAEs present at all frequencies in both ears (BILATERAL PASS). There was no association between DPOAEs (FAIL, UNILATERAL PASS, BILATERAL PASS $)$ and teachers' ages ( $\mathrm{F}[2,64]=1.24, p=0.297)$ or duration of teaching experience $(F(2,64)=0.256$, $p=0.775$, one-factor ANOVA). There was no association between presence of DPOAEs (PASS) and gender $\left(\left[\mathrm{C}^{2}\right]\right.$ $p=0.26$ ).

Regarding distribution according to frequency, DPOAEs were present in $94 \%$ of the teachers' ears $(n=126)$ at $2 \mathrm{kHz}$,
$86.6 \%(n=116)$ at $4 \mathrm{kHz}, 59 \%(n=79)$ at $6 \mathrm{kHz}$, and $33.6 \%$ $(n=45)$ at $8 \mathrm{kHz}$.

A significant difference in amplitude (DPOAEs) was observed when hearing rest and hearing after a working day were compared at frequencies of $2 \mathrm{kHz}$ (mean difference $=0.75, \mathrm{t}(133)=2.03, p=0.044)$ and $4 \mathrm{kHz}$ (mean difference $=0.96, \mathrm{t}(133)=3.25, p=0.001$; - Table 1). With respect to SNR (DPOAEs), a significant difference was observed at frequencies of $2 \mathrm{kHz}$ (mean difference $=1.25$, $\mathrm{t}(133)=2.71, p=0.008)$ and $4 \mathrm{kHz}$ (mean difference $=1.14$, $\mathrm{t}(133)=3.68 . p<0.001$; - Table 2$)$.

A correlation was detected between mean noise level in the classroom and the magnitude of the difference in the signal amplitude at frequencies of $2 \mathrm{kHz}(r=0.183$, $p=0.017)$ and $4 \mathrm{kHz}(r=0.187, p=0.015)$. Noise level was also correlated with the difference between the two measurements for SNR at the frequency of $4 \mathrm{kHz}(r=0.173$, $p=0.023$, unilateral Pearson correlation).

\section{Discussion}

According to the ANSI, ${ }^{5}$ the acceptable level of background noise in the classroom is $35 \mathrm{~dB}(\mathrm{~A})$, and for efficient communication, the relation between background noise and the vocal signal emitted by the teacher must be more than $15 \mathrm{~dB}^{5,10}$ The $\mathrm{ABNT}^{6}$ suggests that background noise should not exceed $50 \mathrm{~dB}(\mathrm{~A})$, and acceptable levels should be between 35 and $45 \mathrm{~dB}(\mathrm{~A})$.

In the present study, the mean noise level measured in the classroom was $76 \mathrm{~dB}(\mathrm{~A})$. In addition to generating inappropriate conditions for learning, this excessive noise may have caused physical and mental exhaustion and hearing loss in teachers. ${ }^{1,11,13}$ Although the SPLs detected were higher than those recommended, they were similar to those reported

Table 1 Mean amplitude in dB of the signal for frequencies of 2, 4, 6, and $8 \mathrm{kHz}$ prior and subsequently to noise exposure during a working day

\begin{tabular}{|l|l|l|l|}
\hline Frequency & $\begin{array}{l}\text { Moment 1 } \\
\text { (at hearing rest) }\end{array}$ & $\begin{array}{l}\text { Moment 2 } \\
\text { (after a working day) }\end{array}$ & $p$-value \\
\hline $2 \mathrm{KHz}$ & $6.22(6.83)$ & $5.48(6.96)$ & $0.044^{*}$ \\
\hline $4 \mathrm{KHz}$ & $-0.66(5.52)$ & $-1.62(5.90)$ & $0.001^{*}$ \\
\hline $6 \mathrm{KHz}$ & $-4.17(8.27)$ & $-4.14(8.73)$ & 0.950 \\
\hline $8 \mathrm{KHz}$ & $-8.57(8.27)$ & $-8.92(8.48)$ & 0.489 \\
\hline
\end{tabular}

Data are reported as mean and standard deviation (SD). Paired $t$-test, $p<0.05$.

Table 2 Mean signal in $\mathrm{dB}$ to noise ratio for frequencies of 2, 4, 6, and $8 \mathrm{kHz}$ prior and subsequent to noise exposure during a working day

\begin{tabular}{|l|l|l|l|}
\hline Frequency & $\begin{array}{l}\text { Moment 1 } \\
\text { (at hearing rest) }\end{array}$ & $\begin{array}{l}\text { Moment 2 } \\
\text { (after a working day) }\end{array}$ & $p$-value \\
\hline $2 \mathrm{KHz}$ & $20.13(7.36)$ & $18.89(7.46)$ & $0.008^{*}$ \\
\hline $4 \mathrm{KHz}$ & $19.38(5.56)$ & $18.24(5.88)$ & $0.001^{*}$ \\
\hline $6 \mathrm{KHz}$ & $15.63(8.38)$ & $15.64(8.75)$ & 0.987 \\
\hline $8 \mathrm{KHz}$ & $9.24(8.53)$ & $8.82(8.61)$ & 0.468 \\
\hline
\end{tabular}

Data are reported as mean and standard deviation (SD). Paired t-test, $p<0.05$. 
in other studies, with means exceeding $60 \mathrm{~dB}(\mathrm{~A}) .^{3,4,7,8}$ As the schools studied are positioned in remote locations along roads with little vehicular or overhead airline traffic, we believe that internal sources were the major cause of sound pollution, as observed in other studies. ${ }^{1,2,7}$

Several studies have been conducted using DPOAEs tests $^{14,19,20}$ to detect sudden cochlear changes due to noise exposure. Despite the insufficiency of investigations involving teaching populations, we selected the DPOEAs tests to assess noise-induced hearing damage in teachers. This choice was made due to the possibility of assessing cochlear activity in a global manner, from basal (high frequencies) to apical (low frequencies), according to specific frequencies with DPOAEs, providing a more extensive analysis of cochlear function.

Some studies have concluded that DPOAEs are useful for the diagnosis of NIHL, ${ }^{21,22}$ although the latter are more efficient for the early diagnosis of individuals with apparently normal hearing. DPOAEs can be used to evaluate responses at high frequencies, which are the first to be involved in noise exposure, and the damage is not detectable by tone audiometry. ${ }^{22}$ A study performed with hospital staff identified that sound pressure levels and exposure time did not influence the attainment of tonal auditory thresholds. However, otoacoustic emissions were more altered as the sound pressure level and the time of exposure were higher. ${ }^{16}$

Marques and Costa $^{9}$ demonstrated an association between absent DPOAEs response and exposure to occupational noise in the frequency range of 3; 4; and $6 \mathrm{kHz}$, which is where initial hearing injuries occur. In the present study, only $16.4 \%$ and $20.9 \%$ of cases met the "pass" (DPOAEs) criterion for both ears and one ear, respectively. Analysis of individual frequencies revealed a progressive reduction in the presence of DPOAEs according to frequency range (the higher the frequency, the lower the prevalence of DPOAEs). This has also been reported by others. ${ }^{16,23}$ Attias $^{24}$ observed that the prevalence of DPOAEs absence increased gradually between $2 \mathrm{kHz}(9 \%)$ and $6 \mathrm{kHz}(52 \%)$. A study involving subjects with normal hearing detected reduced DPOAEs amplitude and SNR relative to a reference group when exposed to noise at all frequencies tested $(2-6 \mathrm{kHz}) .{ }^{17}$ The same study, which only used the SNR $>6$ criterion, showed a lower incidence of DPOAEs at frequencies of 2 and $4 \mathrm{kHz}$ and a higher incidence at the frequency of $6 \mathrm{kHz}$ relative to our results. The left and right ears did not differ significantly with respect to the prevalence of DPOAEs changes, suggesting that exposure occurs in a uniform manner in both ears, and there is no tendency toward hearing loss lateralization. Similar results were reported in a study involving subjects with normal hearing who were exposed to occupational noise (metal industry), with changes in DPOAE in the right and left ears in 72 and $66 \%$ of cases. $^{23}$

In addition, it is worth noting that there were no associations between DPOAEs groups (passes, goes in one ear, failure) and age or duration of exposure. We expected teachers with longer durations of exposure to show worse results, but this hypothesis was not confirmed. Therefore, we believe that this occurred due to changes in outer hair cells in younger teachers due to regular and frequent exposure to non-occupational noise (e.g., MP3 and nightclub music). Young people are now constantly exposed to high levels of sound pressure and already early show changes in outer hair cells. $^{25}$

According to the International Organization for Standardization, 1999: $2013,{ }^{15}$ constant exposure to high SPLs can lead to permanent impairment of the hearing organ, which occurs gradually with months, years, or decades of exposure. Noise-induced permanent threshold shift is usually preceded by a reversible temporary effect known as temporary threshold shift; however, the severity of this shift and recovery from its effects depend on the extent and duration of exposure. These temporary changes can generate a reduction in hearing sensitivity and DPOAE amplitude. $^{18,19,26}$ Studies comparing pre- and post exposure to high sound pressure levels have demonstrated that DPOAE is more sensitive than tone audiometry in monitoring early cochlear changes. ${ }^{20,21}$ Several studies ${ }^{14,20}$ have reported changes in DPOAE amplitude following noise exposure. However, with respect to the frequencies involved, there were differences that may have been related to the type of noise to which the subjects were exposed or the methodology applied.

In the present study, we observed a significant reduction in signal amplitude and DPOAEs SNR at frequencies of 2 and $4 \mathrm{kHz}$ at the end of a working day. A relationship was also detected between mean noise exposure in the classroom and the magnitude of the difference in DPOAEs signal amplitude at frequencies of 2 and $4 \mathrm{kHz}$, and SNR at a frequency of $4 \mathrm{kHz}$. These data led us to conclude that the higher the noise level inside the classroom, the greater the difference between the two time points (with respect to hearing rest and measurement following a working day). That is to say that the higher the noise exposure level, the lower the amplitude of the signal measured following a working day at frequencies of 2 and $4 \mathrm{KHz}$. Because of the difficulty involved in finding studies involving the similar population, we can only compare our results to those obtained in studies in which subjects were exposed to other types of noise. A study conducted prior and subsequent to the use of a walkman at high intensity for 60 minutes demonstrated a significant reduction in DPOAE amplitude at frequencies of 3, 4, and $6 \mathrm{kHz} .^{27}$ With respect to noise produced by firing a gun, a study conducted by Konopka et al. ${ }^{20}$ revealed a mean reduction in response amplitude throughout the range evaluated in 19 of 20 participants, particularly at frequencies of 1 and $3 \mathrm{kHz}$ for the left ear. According to the authors, this difference between ears is a reflex of body posture when shooting. A study involving the practice of physical activity with the use of a walkman at a mean intensity of $90.5 \mathrm{~dB}(\mathrm{~A})$ for 30 minutes reported a decrease in DPOAE response from $100 \%$ prior to exposure to $75 \%$ subsequent to exposure. The higher frequencies, 3,4 , and $5 \mathrm{KHz}$, showed a higher number of failures at the second measurement. ${ }^{26}$ Comparing the results of this research to those described above, it appears that, relative to other frequencies, $4 \mathrm{kHz}$ is affected most with respect to amplitude and SNR. 
Individual who are more sensitive to intense noise, and probably more susceptible to NIHL, tend to show a higher incidence of temporary change in hearing thresholds. ${ }^{21}$ Even in the case that permanent hearing loss is a not the consequence, exposure to noise, even in short periods, can generate a cumulative damage. $^{28}$ In our study, changes in DPOAE may have been associated with the transitory threshold changes and might precede a NIHL. The results showed relationships between average classroom noise levels and the magnitude of the difference in response amplitude at 2 and $4 \mathrm{kHz}$ and SNR at $4 \mathrm{kHz}$. These data suggest that the higher the noise level present in the classroom, the greater the difference between the two moments (with auditory rest and after working hours), and serve to demonstrate that noise in schools can lead to a harmful auditory effects, which is initially temporary but may become permanent with continued exposure.

In addition to improving the acoustics in schools, it is necessary to create public policies to educate students and raise their awareness regarding noise reduction. Currently, the Brazilian legislation that is directed at workers' health requires the monitoring of hearing when there is occupational exposure to noise. Therefore, it is essential that further research focusing on teachers' hearing health is conducted to provide data prompting reconsideration of protective action, both individually and collectively.

\section{Conclusion}

Comparison of the two assessments (prior and subsequent to exposure) revealed significant reduction in signal amplitude and DPOAE SNR at 2 and $4 \mathrm{kHz}$. These data are extremely significant, because the high SPLs that teachers are exposed daily can cause a temporary change in outer hair cells of the organ of Corti, and these changes can become permanent over time.

\section{Conflict of Interests}

The authors have no conflict of interests to declare.

\section{References}

1 Fiorini AC, Matos ECG. Ruído na escola: queixas de saúde e o incômodo em professores do ensino público. Distúrb Comun 2009;21:187-197

2 Eysel-Gosepath K, Daut T, Pinger A, Lehmacher W, Erren T. Effects of noise in primary schools on health facets in German teachers. Noise Health 2012;14(58):129-134

3 Campos NB, Delgado-Pinheiro EMC. Noise analysis and intervention in speech school environment: regular private and public schools. Rev CEFAC 2014;16:83-90

4 Rabelo ATV, Santos JN, Oliveira RC, Magalhães MC. Efeito das características de salas de aula na inteligibilidade de fala dos estudantes. CoDAS 2014;26:360-366

5 American National Standard Institute ANSI/ASA S12. 60-2002. Acoustical Performance Criteria, Design Requirements, and Guidelines for Schools. Washington American National Standard Institute; 2002

6 Associação Brasileira de Normas Técnicas (ABNT). NBR 10152. Níveis de ruído para o conforto acústico - procedimento. Rio de Janeiro: Associação Brasileira de Normas Técnicas; 1987
7 Almeida Filho ND, Filletti F, Guillaumon HR, Serafini F. Intensity of noise in the classroom and analysis of acoustic emissions in schoolchildren. Int Arch Otorhinolaryngol 2012;16:91-95

8 Lopes BM, Calaço SLF, Marcia S-Z. Ações para a melhoria do conforto acústico em instituições de educação infantil. Ciênc. Saúde Colet (Barueri) 2018;23:315-324

9 Marques FP, da Costa EA. Exposure to occupational noise: otoacoustic emissions test alterations. Rev Bras Otorrinolaringol (Engl Ed) 2006;72(03):362-366

10 World Health Organization (WHO) Guideline for community noise. London; 1999

11 Barros SMdS, Frota S, Atherino CCT, Osterne F. The efficiency of otoacoustic emissions and pure-tone audiometry in the detection of temporary auditory changes after exposure to high sound pressure levels. Rev Bras Otorrinolaringol 2007;73:592-598

12 OSHA [Internet]. OSHA - Occupational Safety and Health Administration; c2018 [cited 2018 Jan 08]. Available from: http://www. osha.gov

13 Pimentel BN, Fedosse E, Rodrigues NdGS, Cruz KS, Santos Filha VAVd. Perception of noise, hearing health and quality of life of public school teachers. Audiol Commun Res 2016;21:1740

14 Frota S, Iorio MCM. Distortion-product otoacoustic emissions and pure tone audiometry: a study of temporary threshold shifts. Rev Bras Otorrinolaringol 2002;68:15-20

15 Geneva: International Organisation for Standardisation; 2013. ISO 1999: 2013 Acoustics - Estimation of Noise-Induced Hearing Loss

16 Iizuka Letícia Yurie. Gil Daniela. Audiological evaluation in employees exposed to noise in a public hospital. Rev CEFAC 2014;16:715-722

17 Atchariyasathian V, Chayarpham S, Saekhow S. Evaluation of noiseinduced hearing loss with audiometer and distortion product otoacoustic emissions. J Med Assoc Thai 2008;91(07):1066-1071

18 Korres GS, Balatsouras DG, Tzagaroulakis A, Kandiloros D, Ferekidou E, Korres S. Distortion product otoacoustic emissions in an industrial setting. Noise Health 2009;11(43):103-110

19 Silva PB, Fiorini AC, Azevedo AF. Estudo das emissões otoacústicas em indivíduos expostos a ruído de bateria universitária. Rev CEFAC 2017;19:645-653

20 Konopka W, Zalewski P, Pietkiewicz P. Evaluation of Transient and Distortion Product Otoacoustic Emissions before and after shooting practice. Noise Health 2001;3(10):29-37

21 Negrão MA, Soares E. Variation in amplitudes of evoked otoacoustic emissions and suceptibility to hearing loss induzed by noise -HLIN. Rev CEFAC 2004;6:414-422

22 Baradarnfar MH, Karamifar K, Mehrparvar AH, et al. Amplitude changes in otoacoustic emissions after exposure to industrial noise. Noise Health 2012;14(56):28-31

23 Boger M, Sampaio ALL. Oliveira CACPd. Distortion product otoacoustic emissions in normal-hearing workers exposed to occupational noise. Rev. Eletrônica Gest. Saúde 2013;4:200-212

24 Attias J, Horovitz G, El-Hatib N, Nageris B. Detection and clinical diagnosis of noise-induced hearing loss by otoacoustic emissions. Noise Health 2001;3(12):19-31

25 Hanazumi A, Gil D, lório MCM. Hearing habits and audiological evaluation in adults. Audiol Commun Res 2013;18:179-185

26 Cortes - Andrade IF. De Souza ADS, Frota SMMC. Distortion product evoked otoacoustic emissions study with individuals of a fitness gym. Rev CEFAC 2009;11:654-661

27 Silveira JAM, Brandão ALA, Rossi JD, et al. Avaliação da alteração auditiva provocada pelo uso do walkman, por meio da audiometria tonal e das emissões otoacústicas (produtos de distorção): estudo de 40 orelhas. Rev Bras Otorrinolaringol 2001;67:650654

28 Correa BM, Silveira AFd, Bonfante D, Costa MJ, Biaggio EPV. Habits and hearing complaints of teenagers users of personal stereos. Rev CEFAC 2016;18:348-354 